\title{
UNDERCOOLING RELATED CASTING DEFECTS IN SINGLE CRYSTAL TURBINE BLADES
}

\author{
M. Meyer ter Vehn, D. Dedecke, U. Paul* and P.R. Sahm \\ Gießerei-Institut, RWTH Aachen, Intzestr. 5, 52056 Aachen, Germany \\ * now at: Siemens KWU, Wiesenstr. 35, 45473 Mülheim/Ruhr, Germany
}

\begin{abstract}
$\underline{\text { Abstract }}$
During the single crystal solidification of turbine blades casting defects such as stray grains are often formed in the inner and outer shroud due to a curvature of the liquidus isotherm and a resulting thermal undercooling of the melt. An intensive study of the thermal conditions in typical shroud regions for two different blade geometries was carried out using macroscopic solidification modeling and temperature measurements during casting experiments. It was tried to reduce undercooling related defects by temporarily changing the withdrawal velocity of the mold and by positively influencing the heat flux with ceramic insulation. In addition to that the application of grain continuators was investigated in order to eliminate stray grains while casting large blades for use in stationary turbines.
\end{abstract}

\section{Introduction}

Avoiding structural inhomogeneities during single crystal solidification has always been a major point of interest to the investment casting engineer involved with the production of high temperature components, such as single crystal turbine blades. In order to use the full potential of these components it is necessary to optimize the Bridgman process for a resulting defect-free as-cast structure and for better results during the subsequent heat treatment.

Casting defects can be caused by a macroscopic curvature of the liquidus isotherm while it is passing through extreme enlargements in the cross-section of the component (e.g. transition from the blade to the outer shroud) [1]. A concave shaped liquidus isotherm can result in isolated, thermally undercooled regions of melt. Depending on the number of nuclei in the melt and the extent of thermal undercooling this Inay lead to heterogeneous nucleation close to or at the ceramic mold and the formation of spurious grains, Figure 1a. If a high angle boundary is formed the casting will not be accepted [2]

If nucleation is suppressed secondary dendrites will grow rapidly lateral towards the far corners of the shroud as soon as the primary dendrites reach the transition from blade to shroud resulting in a fine dendritic microstructure in this region, Figure $1 \mathrm{~b}$. This rapidly solidified structure is believed to have a slightly increased tendency to recrystallize during heat treatment because of its distorted lattice (mosaic structure) [1]. A convex shaped liquidus isotherm may hinder sufficient feeding and therefore cause open interdendritic micro porosity on the upper side of the shroud.

$$
\text { Superalloys } 1996
$$

Edited by R. D. Kissinger, D. J. Deye, D. L. Anton,

A. D. Cetel, M. V. Nathal, T. M. Pollock, and D. A. Woodford

The Minerals, Metals \& Materials Society, 1996
It has often been recognized that thermal undercooling in the shroud of a turbine blade causes changes in the conditions for dendritic growth [3]. This paper concentrates on macroscopic undercooling phenomena during single crystal solidification of turbine blades, in particular on the effect of blade geometry and of changes in the process parameters on the resulting microstructure.

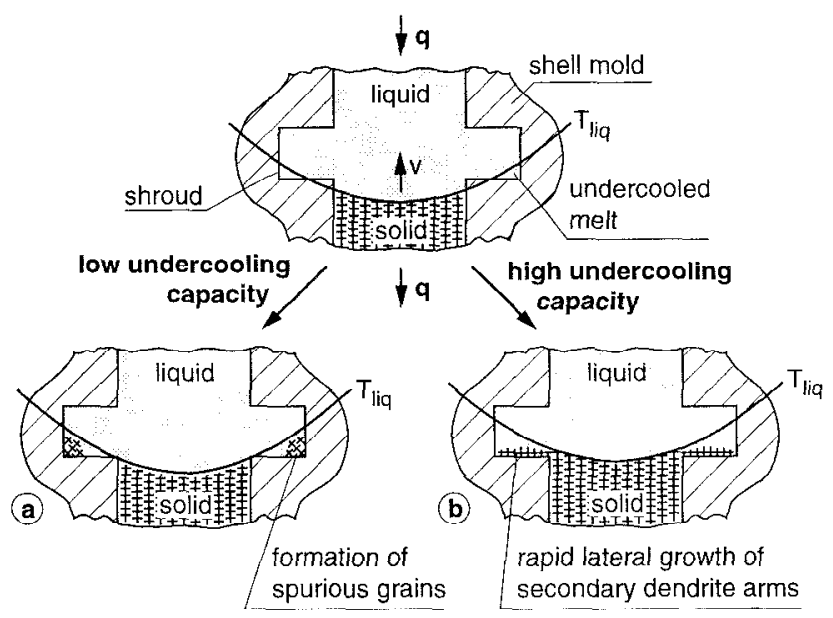

Figure 1: Depending on the undercooling capacity of the given alloy a macroscopic concave curvature of the liquidus isotherm can cause the formation of stray grains (a) or result in fast lateral growth of secondary dendrites (b).

\section{Experimental procedure}

Macroscopic solidification modeling was used to detect critical component areas that are crucial with regard to maintaining the single crystal dendrite structure during solidification and heat treatment. Temperature measurements during solidification with thermocouples in these regions enabled a reconstruction of the liquidus isotherm. Metallographic inspection of macro- and microstructure was used to analyze type and cxtent of casting defects. Correlation of the metallographic results with the simulated and measured course of the liquidus isotherm gave information about the origin of casting defects. 
Two different blade geometries were investigated. The first, which was approximately $18 \mathrm{~cm}$ high, resembled a typical airfoil for use in aerospace engines, Figure 2. It had a simple ceramic core, and was cast in a 4 blade cluster with the Nibase superalloy CMSX-6. The second geometry, which was approximately $30 \mathrm{~cm}$ high, was designed to give generally valid information about the solidification of large turbine blades for land-based turbines, Figure 3. It has an inner shroud only and was cast solid and tip down as a single blade with the alloy SC 16. Alloy compositions of CMSX-6 and SC 16 as well as other alloy data are given in Table $\mathrm{I}$.
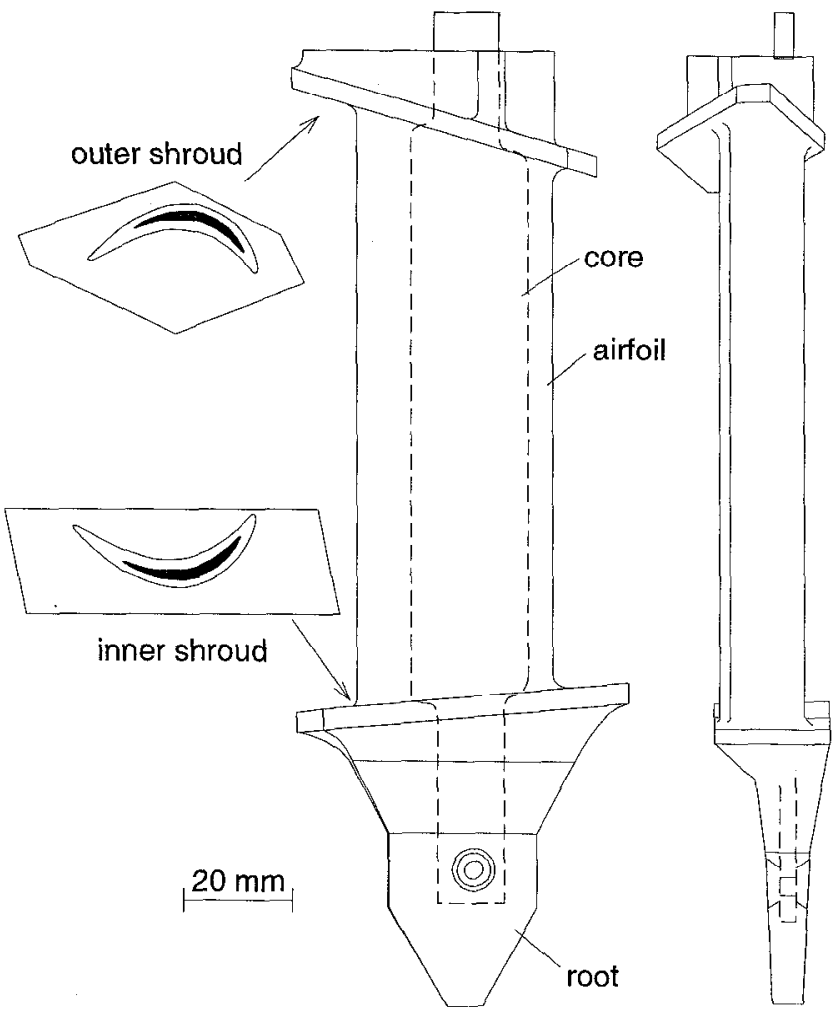

Figure 2: The small dummy blade has an inner and an outer shroud. The blade around the core has a thickness of about $1.5 \mathrm{~mm}$. Four blades were assembled around a ccntral runner rod in a cluster and thermocouples were placed in the outer shrouds.

Table I: Nominal compositions (wt.-\%), densities and approximate liquidus temperatures for CMSX-6 and SC 16.

\begin{tabular}{rcc}
\hline & CMSX-6 & SC 16 \\
\hline $\mathrm{Cr}$ & 9.8 & 16.0 \\
$\mathrm{Co}$ & 5.0 & - \\
$\mathrm{Mo}$ & 3.0 & 3.0 \\
$\mathrm{Ta}$ & 2.0 & 3.5 \\
$\mathrm{AI}$ & 4.8 & 3.5 \\
$\mathrm{Ti}$ & 4.7 & 3.5 \\
$\mathrm{Hf}$ & 0.01 & - \\
$\mathrm{C}$ & 0.02 & - \\
$\mathrm{N}$ & $10 \mathrm{ppm}$ & - \\
$\mathrm{O}$ & $9 \mathrm{ppm}$ & - \\
$\mathrm{Ni}$ & bal. & bal. \\
\hline density $\mathrm{\rho}(\mathrm{g} / \mathrm{cm} 3)$ & 7.98 & 8.21 \\
\hline liquidus temp. $\left.{ }^{\circ} \mathrm{C}\right)$ & 1337 & 1338 \\
\hline
\end{tabular}

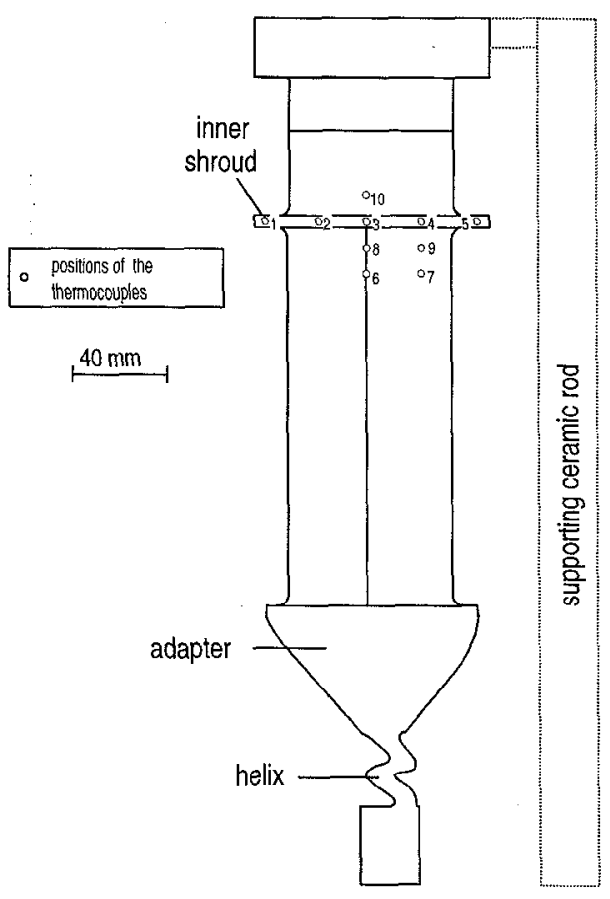

Figure 3: Casting set-up of the large dummy turbine blade

Macroscopic solidification modeling of the small blade was carried out with the finite element code CASTS (Computer Aided Solidification TechnologieS) [4], which has been developed at the Gießerei-Institut and ACCESS (Aachen Center for Solidification in Space). The digital description of furnace and blade including shell mold as well as the subscquent FE mesh generation were performed with commercial software (IDEAS supertab). Due to the cluster's cyclic symmetry the mesh consists of $1 / 4$ of the cluster including starter, helix, central runner and gating system. It has 47,704 volume elements (tetraeders, pentaeders and hexaeders) and 3,441 surface elements, Figure 4.

CASTS calculates the 3D temperature distribution taking into account the release of latent heat and the heat transfer at interfaces between different materials [5]. Because of the nature of the bridgman process natural convection was neglected. Since thermal radiation is the dominant heat transmission mechanism in the vacuum casting process the net radiation method [6] was used to calculate heat exchange between all radiating surfaces. The transient temperature distribution and the macroscopic shape and progress of the liquidus isotherm were later visualized with the CASTS-tool COLOR3D.

The SC casting experiments were performed in a vacuum bridgman furnace (Leybold IS8/III). A round chill plate of $15 \mathrm{~cm}$ diameter and a $17.6 \mathrm{~cm}$ diameter baffle were used for the clusters of the smaller blades. The chill plate for the larger blades had the shape of a parallelogram, just like the corresponding baffle. $\mathrm{Al}_{2} \mathrm{O}_{3} / \mathrm{SiO}_{2}$-ceramic molds were manufactured by investment process. Up to 20 thermocouples per mold were positioned in and close to the shrouds of the blades. For both geometries a withdrawal velocity $\left(v_{\text {mold }}\right)$ of $3 \mathrm{~mm} / \mathrm{min}$ and a heater temperature of $1550^{\circ} \mathrm{C}$ were standard process parameters of the Bridgman furnace.

In order to reduce or even eliminate casting defects by smoothing the curvature of the liquidus isotherm the with- 

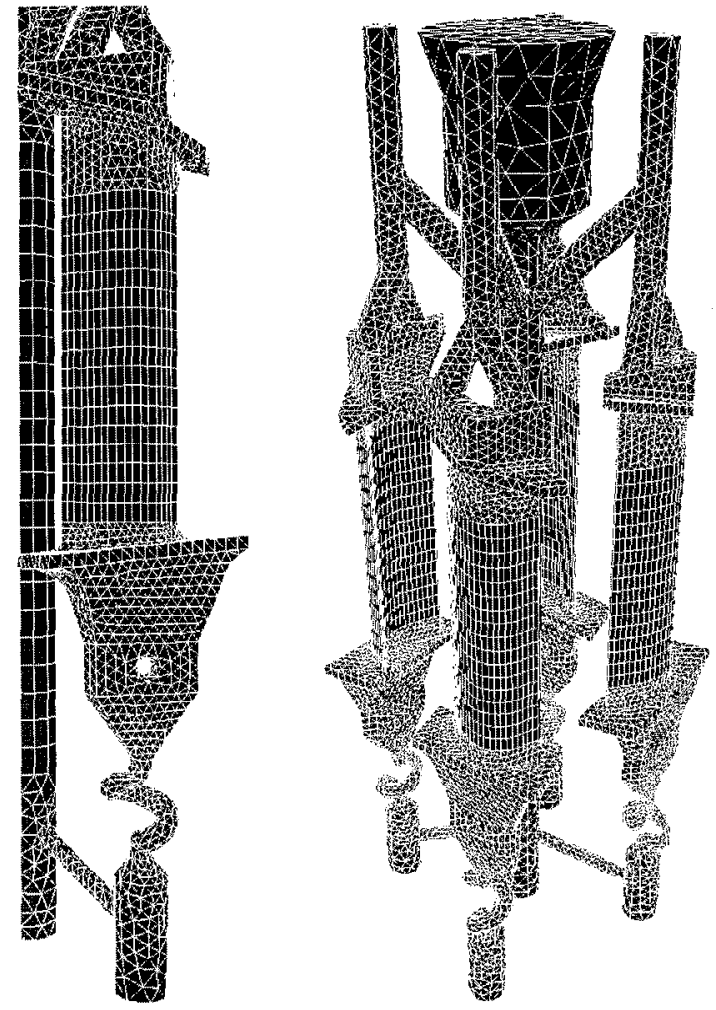

Figure 4: FEM-mesh of the small dummy blade.

drawal rates were varied ( 1 to $4 \mathrm{~mm} / \mathrm{min}$ ) while the solidification front was passing the critical shroud areas. In addition to that it was tried to minimize the thermal undercooling in the shroud of the larger blades by applying insulation to the ceramic mold just below the shroud. Another means to avoid casting defects is the use of grain continuators [7]. A grain continuator is a simple rod (diameter: $6 \mathrm{~mm}$ ) with which the single crystal orientation selected by the helix is transferred from just above the helix to critical regions in the shroud.

\section{Results and Discussion}

\section{Small dummy blade}

FEM solidification modeling. For a constant withdrawal velocity $\left(v_{\text {mold }}=3 \mathrm{~mm} / \mathrm{min}\right)$ the simulation shows a concave curved liquidus isotherm in the outer shroud of the small airfoil during solidification, Figure 5a. Part of the shroud on the leading edge is well below the liquidus-temperature, but since it is isolated from the solidification front in the airfoil and since the alloy has a certain capacity to undercool, it will remain liquid until secondary dendrites are able to grow into the platform or until a stray grain will nucleate due to excessive undercooling.

On the other side of the outer shroud, facing the central runner rod of the cluster, another large thermally undercooled zone can be identified, Figure $5 b$. Looking at the bottom side of the shroud it becomes distinct that this zone is connected with the undercooled volume in the overhanging shroud area at the leading edge, Figure $5 \mathrm{c}$. This area is difficult to access with thermocouples because of the position of the airfoil within the cluster. Therefore, only the simulation can give detailed information about the solidification sequence in this part of the component. A view onto the trailing edge of the blade shows another small isolated undercooled area in the outer shroud, Figure 5d.

Temperature measurements. Temperature measurements in the outer shroud during the solidification experiments with standard parameters revealed an undercooling of about $10 \mathrm{~K}$ below an approximate liquidus-temperature of $1337^{\circ} \mathrm{C}$ in the overhanging shroud area at the leading edge (thermocouple No. 10), Figure 6a. In another set of casting experiments undercoolings of about $12 \mathrm{~K}$ were measured at the opposite side of the shroud (trailing edge, thermocouple No. 19), Figure $6 \mathrm{~b}$. The cooling curves of the thermocouples in the far corner at the leading edge show a small recalescence upon the sudden release of latent heat, whereas no recalescence was observed on the other side at the trailing edge. The extent of this recalescence depends on the amount of heat being released and the conditions of heat flux.

The curvature of the reconstructed liquidus isotherms, some of which are plotted in Figure 7 for both sides of the shroud (leading and trailing edge), is in good agreement with the simulated results. Figure 7 also illustrates the positions of the thermocouples. The vertical temperature gradients necessary for the reconstruction of the isotherms were measured with thermocouples No. 6,7,8 and 9 on the leading edge and thermocouples No. 11 and 20 on the trailing edge.

Metallography. Metallographically prepared cross-sections of the outer shroud show an area of primary dendrites around the core, which have grown from the airfoil into the shroud, Figure 8a. A deviating fine dendritic structure formed by fast lateral growth of secondary dendrites into the areas that were undercooled is visible in the regions far away from the core. In the far corner of the leading edge, where a considerable undercooling was measured, the structure is very fine.

Some castings also showed a stray grain in this area as well as in other undercooled regions, Figure $8 \mathrm{~b}$. Comparing all measured cooling curves with the corresponding micrographs it seems that lateral growth of secondary dendrites without nucleation of stray grains is accompanied with the occurrence of small recalescences, whereas no recalescences were observed, when stray grains were formed.

Variation of withdrawal velocity. A change of the withdrawal velocity at approximately $70 \mathrm{~mm}$ below the outer shroud down to $2 \mathrm{~mm} / \mathrm{min}$ was carried out in order to minimize structural inhomogeneities by reducing the concave curvature of the liquidus isotherms before the shroud started to solidify. Furthermore, it was tried to deliberately provoke stray grains by raising the withdrawal velocity up to $4 \mathrm{~mm} / \mathrm{min}$ in order to define critical parameters for the given geometry and the given alloy.

By reducing the withdrawal velocity it was possible to lower thermal undercooling in the overhanging shroud area at the leading edge to $2 \mathrm{~K}$, Figure 9 . Still, the above described fine dendritic structure was observed. By raising the velocity cooling rates and extent of undercooling in the critical regions increased, Figure 10. Nevertheless, this had no clear effect on the formation of spurious grains. This may be explained by the fact that even though it was possible to influence the extent of undercooling the overall curvature of the liquidus isotherm did not change much. Simulated results illustrate the situation: By raising the velocity from $2 \mathrm{~mm} / \mathrm{min}$ to $4 \mathrm{~mm} / \mathrm{min}$ the solidification front is shifted from the heater zone into the baffle, but no significant effect on the curvature of the isotherm is noticeable, Figure 11. Still, a view onto the 

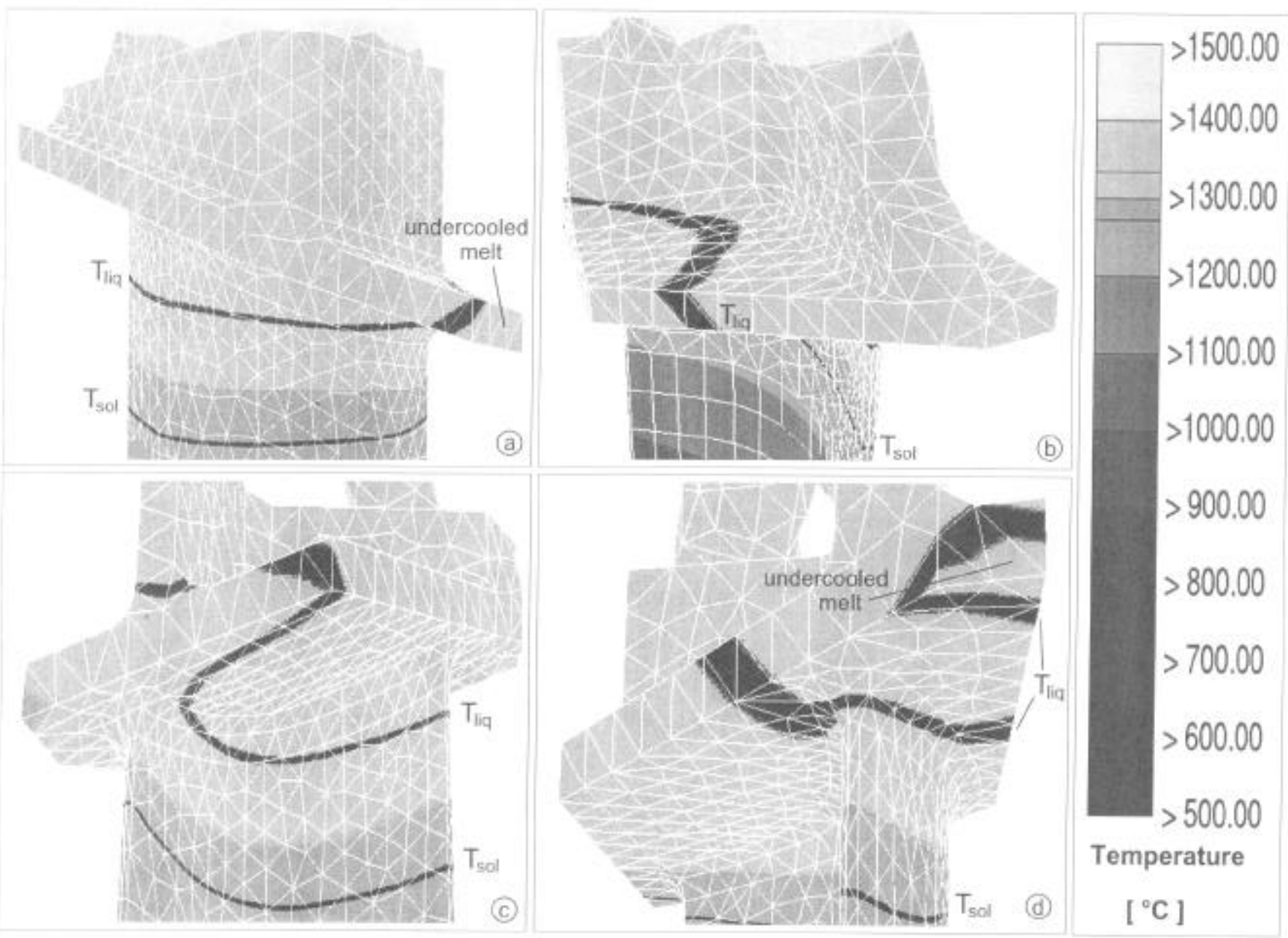

Figure 5: Temperature distribution in the outer shroud of the small blade. Several undercooled regions of melt are visible at the leading edge (a), towards the central runner rod (b and $c$ ) and at the trailing edge (d).

trailing edge of the outer shroud shows that the undercooled zone is becoming smaller as the velocity is changed from $3 \mathrm{~mm} / \mathrm{min}$ to $2 \mathrm{~mm} / \mathrm{min}$, Figure 12 . By lowering the undercooling in the critical areas the chance of spurious grain formation is reduced.

The occurrence of high angle boundaries due to undesired nucleation seemed to be rather the exception at the higher withdrawal velocity ( $\mathrm{v}_{\text {mold }}=4 \mathrm{~mm} / \mathrm{min}$ ) even though higher undercoolings were measured, Figure 13. It remains to be investigated. however, if the fast grown structure will cause recrystallisation during heat treatment. The alloy CMSX-6 proved to be relatively well "undercoolable" which is confirmed by other recent experiments by the authors investigating the maximum undercooling capacity of superalloys in ceramic molds.

\section{Large dummy blade}

Simply because of their larger size, undercooling phenomena caused by the curvature of the liquidus isotherm create a bigger problem during the single crystal solidification of turbine blades for stationary gas turbines. Hence the intention of temperature measurements during the solidification of large dummy turbine blades was to transfer present results onto a more extreme geometry and to find additional appropriate means to reduce casting defects.

Variation of process parameters. Using a constant withdrawal rate of $3 \mathrm{~mm} / \mathrm{min}$ measured temperature curves showed high undercoolings of up to $40 \mathrm{~K}$ below an approximate liquidustemperature of $1338^{\circ} \mathrm{C}$ in the outer regions of the shroud (alloy: SC 16), Figure 14, which generated a fine-grained structure, Figure 15. The reconstructed liquidus isotherm was of a concave shape and had a relatively stable position about 10 to $20 \mathrm{~mm}$ above the baffle in the heater zone of the Bridgman furnace. With the intention of pushing up the liquidus isotherm further into the heater zone, the withdrawal velocity was decreased to $1 \mathrm{~mm} / \mathrm{min} 70 \mathrm{~mm}$ before the shroud passed the baffle (as it was done with the small dummy blades). The experiments resulted in a slightly convex curvature of the liquidus isotherm and in a decrease of recalescence. No significant effect on the undercooling was detected, but the fine-grained zone was much smaller and only a few large stray grains were observed in the far comers of the shroud.

By applying a $\mathrm{SiO}_{2}-\mathrm{Al}_{2} \mathrm{O}_{3}$-insulating-blanket $40 \mathrm{~mm}$ below the shroud of the big dummy blade it was intended to reduce the heat flux between heating and cooling zone. It was possible to minimize the formation of small grains because the 

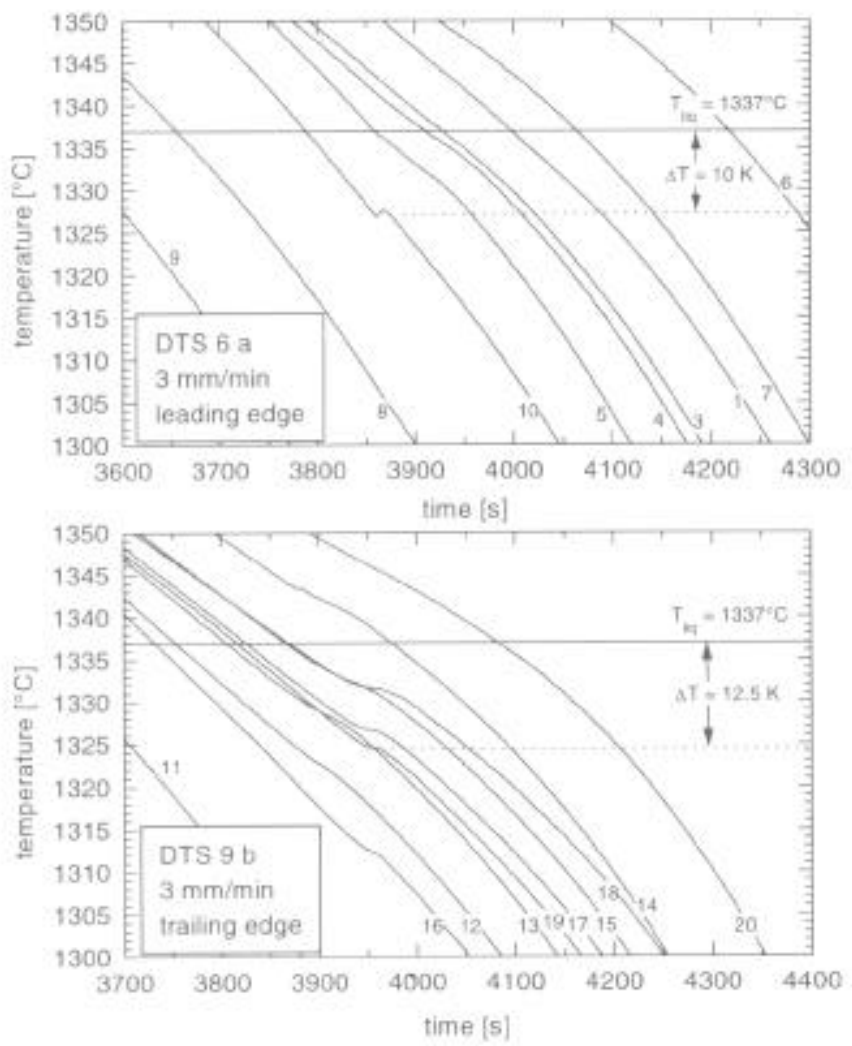

Figure 6: Cooling curves of the thermocouples at the leading edge (a) and at the trailing edge (b) for a withdrawal velocity of $\mathrm{v}=3 \mathrm{~mm} / \mathrm{min}$. Note the undercoolings of thermocouples No. 10 and No. 19.

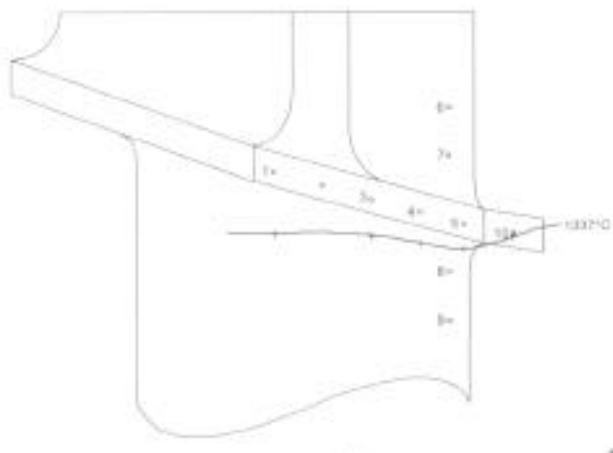

(a)

$10 \mathrm{~mm}$

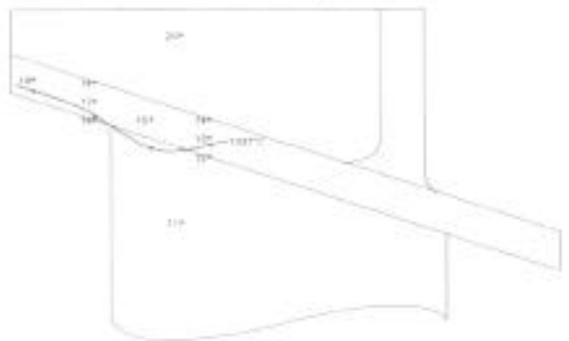

(b)

$10 \mathrm{~mm}$

Figure 7: Reconstructed liquidus isotherms $\left(1337^{\circ} \mathrm{C}\right)$ for the leading edge (a) and the trailing edge (b) are in good agreement with the simulated results.

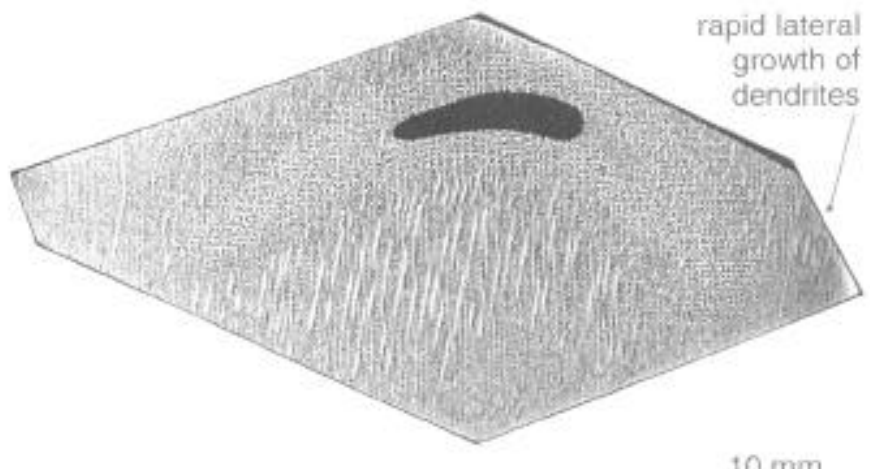

(a)

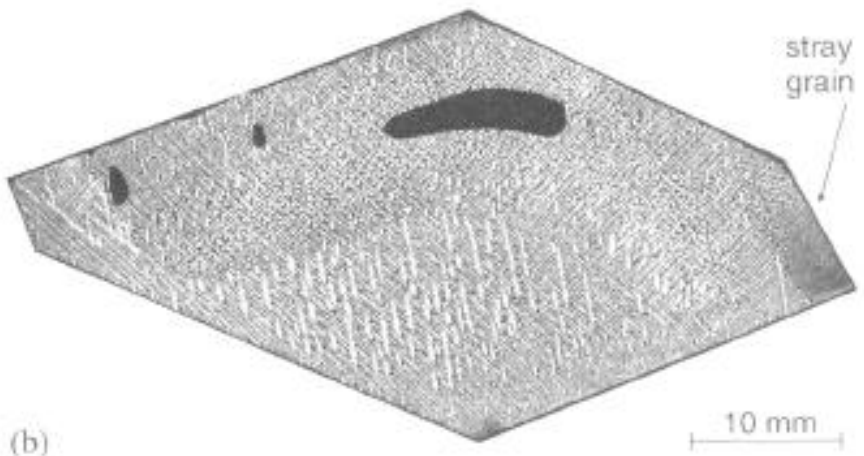

Figure 8: Dendrite structure in the cross-sections of the outer shroud is characterized either by fast grown secondary dendrites (a) or by stray grains (b) in the regions prone to undercool.

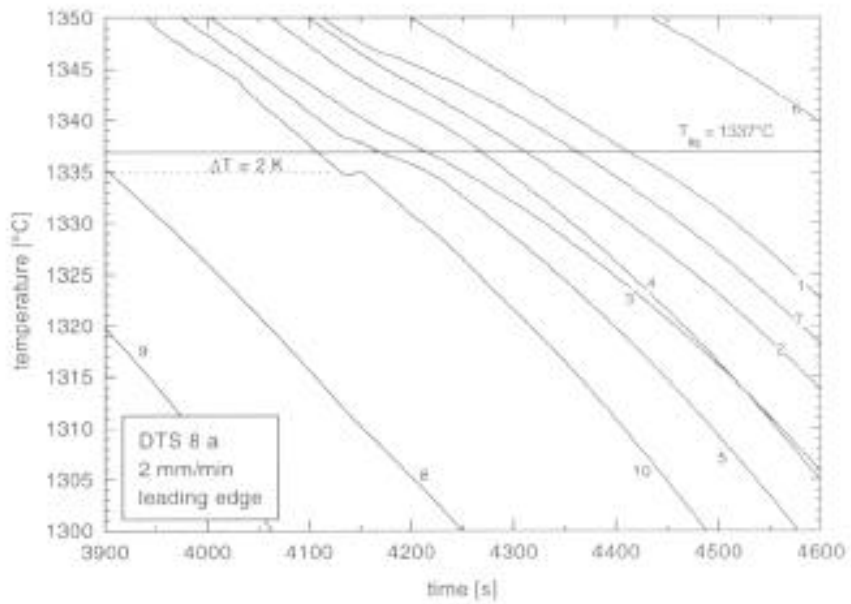

Figure 9: Changing the withdrawal velocity down to $2 \mathrm{~mm} / \mathrm{min}$ reduces the undercooling to $2 \mathrm{~K}$ in the overhanging area at the leading edge. 


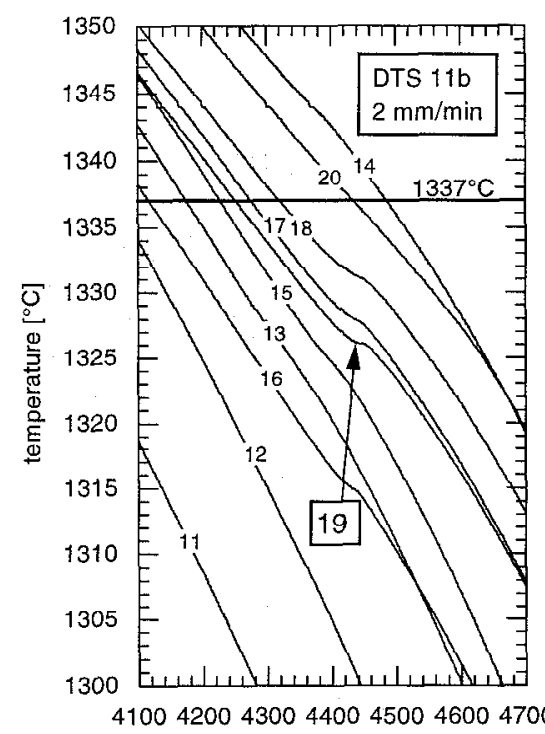

time [s]

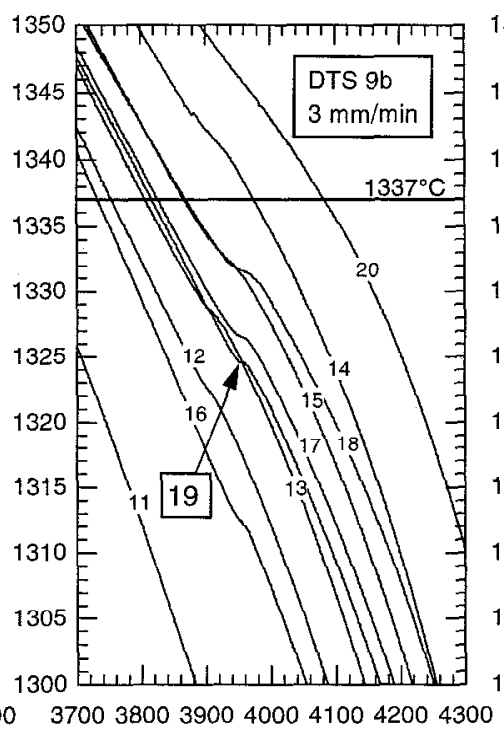

time $[\mathrm{s}]$

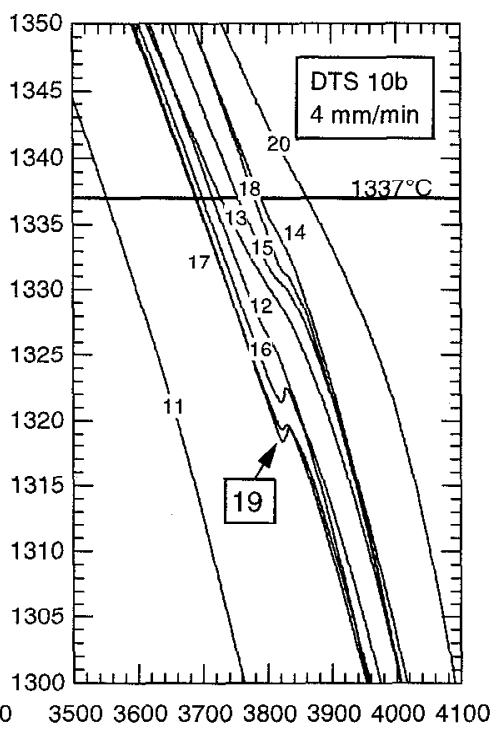

time [s]

Figure 10: Cooling curves measured in the trailing edge at different withdrawal velocities. Raising the velocity causes an increase of the cooling rate and of the extent of undercooling.
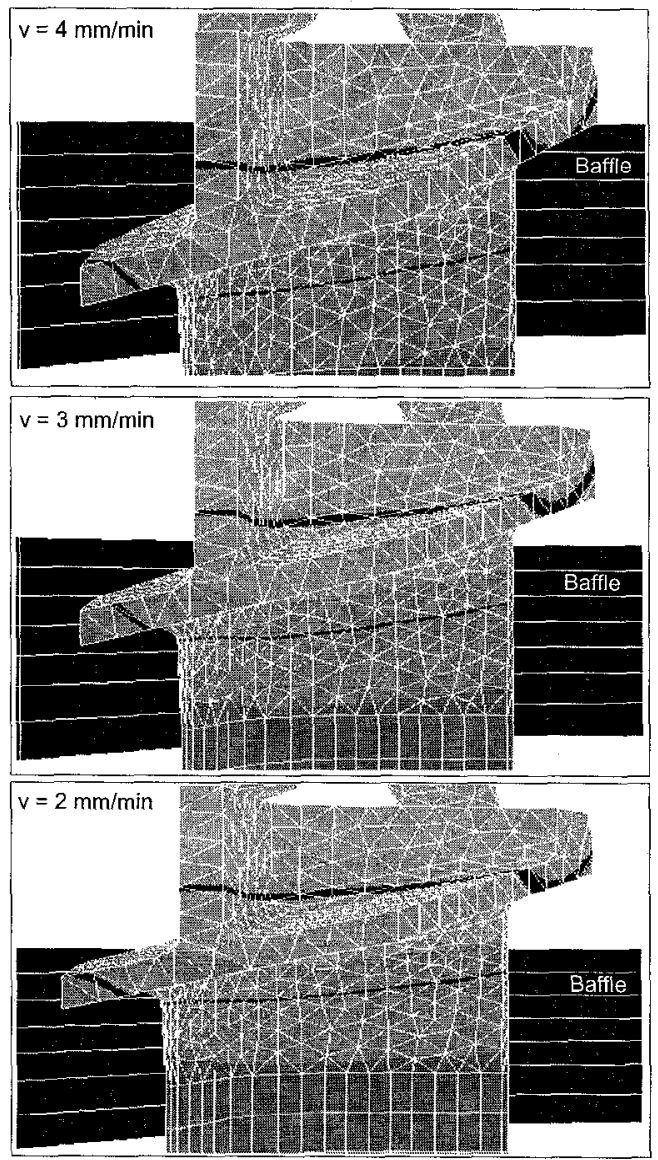

Figure 11: The higher the withdrawal velocity the more the liquidus isotherm will be shifted into the baffle. Still, the effect on the curvature of the isotherm is relatively small.

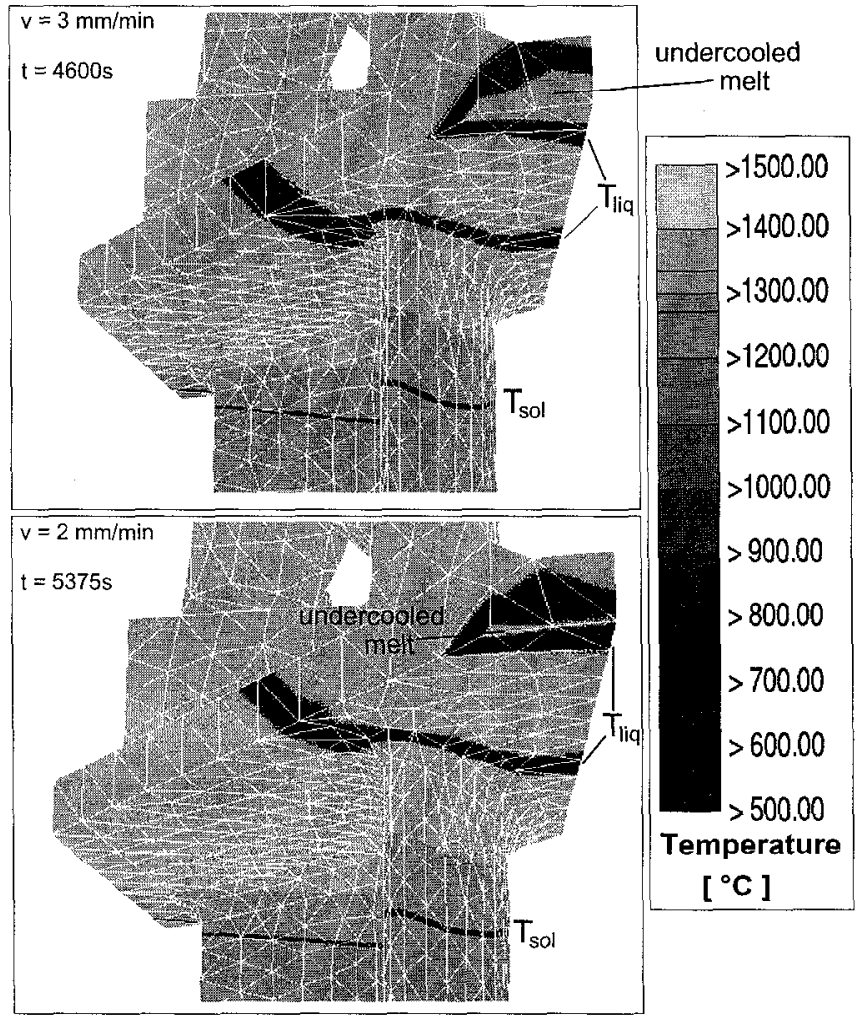

Figure 12: The volume of undercooled melt at the trailing edge increases as the withdrawal velocity goes up. 


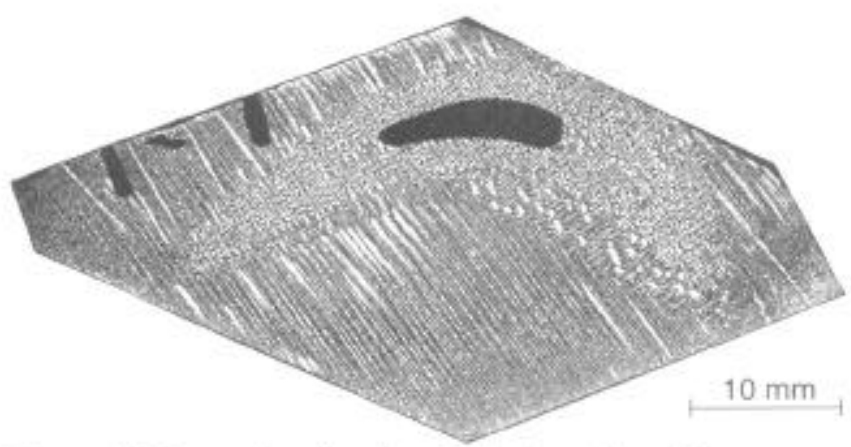

Figure 13: Even though the highest undercoolings were measured at a withdrawal velocity of $4 \mathrm{~mm} / \mathrm{min}$ no stray grains were formed, instead the structure is characterized by excessive lateral growth of secondary dendrites.

temperature loss out of the edges of the outer platform and therefore the undercooling effect decreased. The combination of reducing the withdrawal rate and application of insulation produced the best structure with almost no spurious grains. The recalescences were very small and a fine dendritic structure of fast grown secondary dendrites was dominant in the edges of the shroud comparable to the structure observed in the outer shroud of the small dummy blades, Figure 16.

Grain continuators. Two types of continuators were tested: a single version and a twin version, which was supposed to transfer the single crystal into two corners of the shroud. In order to make successful use of grain continuators it is important not to produce any misorientated grains while the single crystal orientation is transferred to the critical regions of the shroud. Investigations concentrated on possible

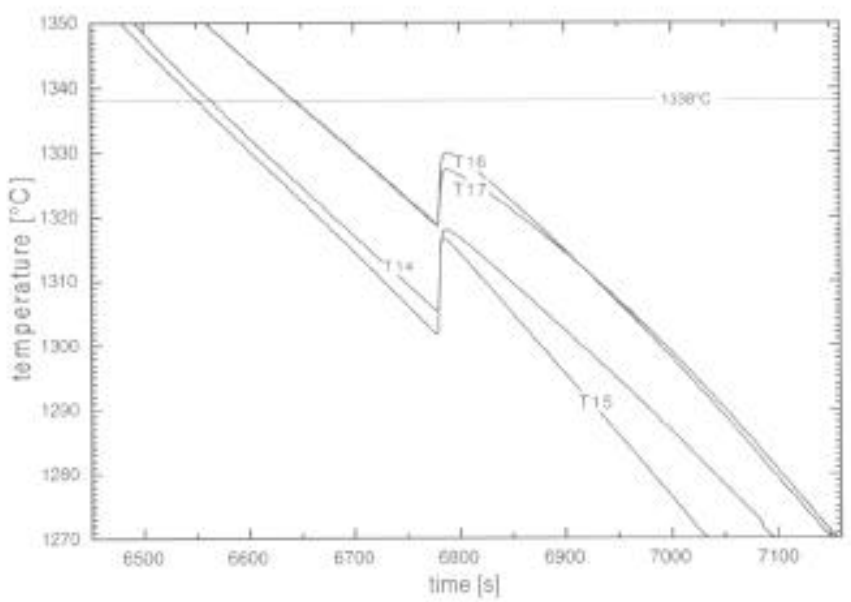

Figure 14: Cooling curves obtained with thermocouples in the outer regions of the shroud of the large dummy blade. The positions of the thermocouples $14,15,16$ and 17 in the shroud are illustrated in Figure 15.

nucleation sites at the lead-off angle just above the belix. Using different angles $\left(\alpha=0^{\circ}, 45^{\circ}\right.$ and $60^{\circ}$, Figure 17a) it was always possible to transfer the single crystal from the adapter to the main body of the continuator, which was about $200 \mathrm{~mm}$ long. No defects were detected over the whole length of both the single and the twin version of the grain continuators.

Next, the solidification front in the grain continuator has to progress faster than in the blade, so it will reach the shroud before it is undercooled. Temperature measurements with thermocouples placed in the same vertical positions below the
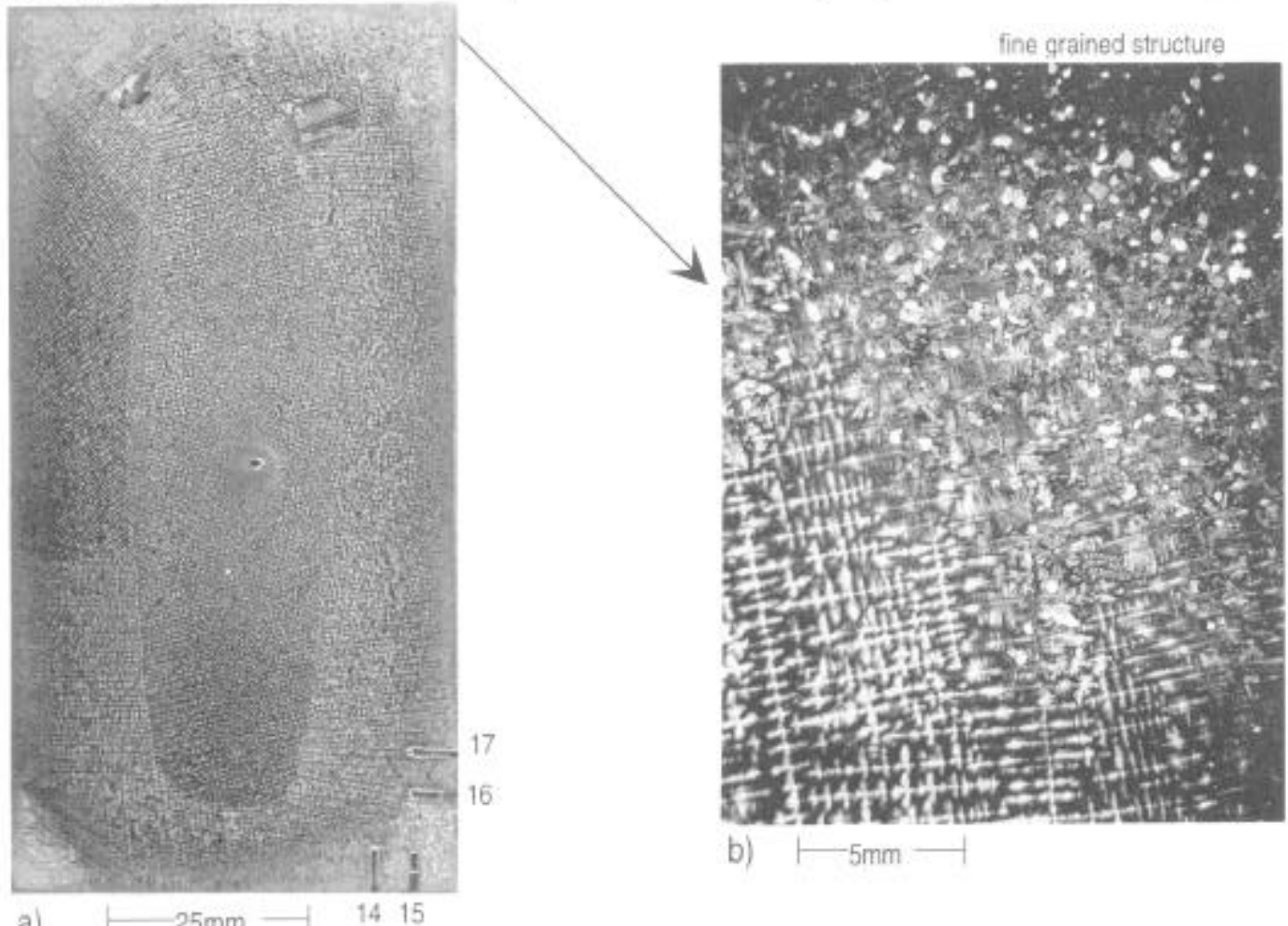

b)

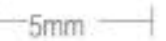

a)

Figure 15: The dendrite structure in the platform shows large misoriented grains (a). The large undercoolings in the corners of the shroud caused a fine grained structure (b). 


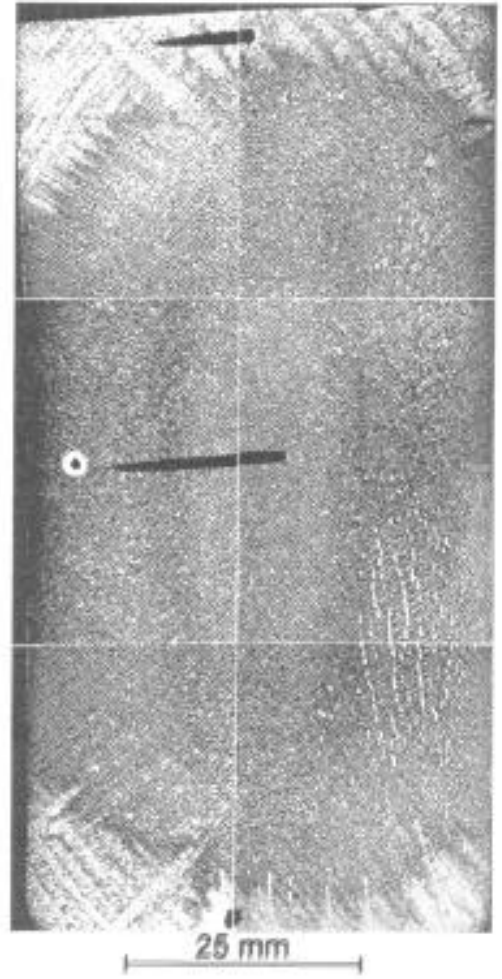

Figure 16: Using insulation in order to minimize the heat flux and additionally optimizing the withdrawal rate resulted in a fine structure of secondary dendrite arms in the corner areas. shroud in the blade and in the continuator showed that the liquidus isotherm in the contiuator is clearly ahead. The bypassed single crystal orientation was transferred successfully into the critical regions of the shroud. Cross-sections of the platform show the positive influence of the continuator, Figure $17 \mathrm{~b}$. Primary dendrite axes are visible in the center as well as on the side of the shroud where the continuator was attached. Between the two areas the structure is characterized by lateral grown secondary dendrites. The formation of spurious grains was completely suppressed on this side. On the opposite side spurious grains could not be avoided. In a realistic casting set-up of several large blades in a cluster the fact that one blade influences the thermal conditions of another because of its shadow may be used to get good results with just a few precisely positioned grain continuators.

Further investigations will have to deal with the possible chance of the formation of low angle boundaries in the shroud in case that the orientation of the dendrite arms will slightly twist as the single crystal is growing inside of the grain continuator.

\section{Conclusion}

The combined use of numerical solidification modeling, temperature measurements and structural analysis has proven to be a practical tool while working on explaining and avoiding casting defects.

The variation of process parameters showed good results for the defect-free solidification of "small" airfoils. It was possible to positively influence the strong effect of extreme cnlargements in the blade on the microstructure formation in
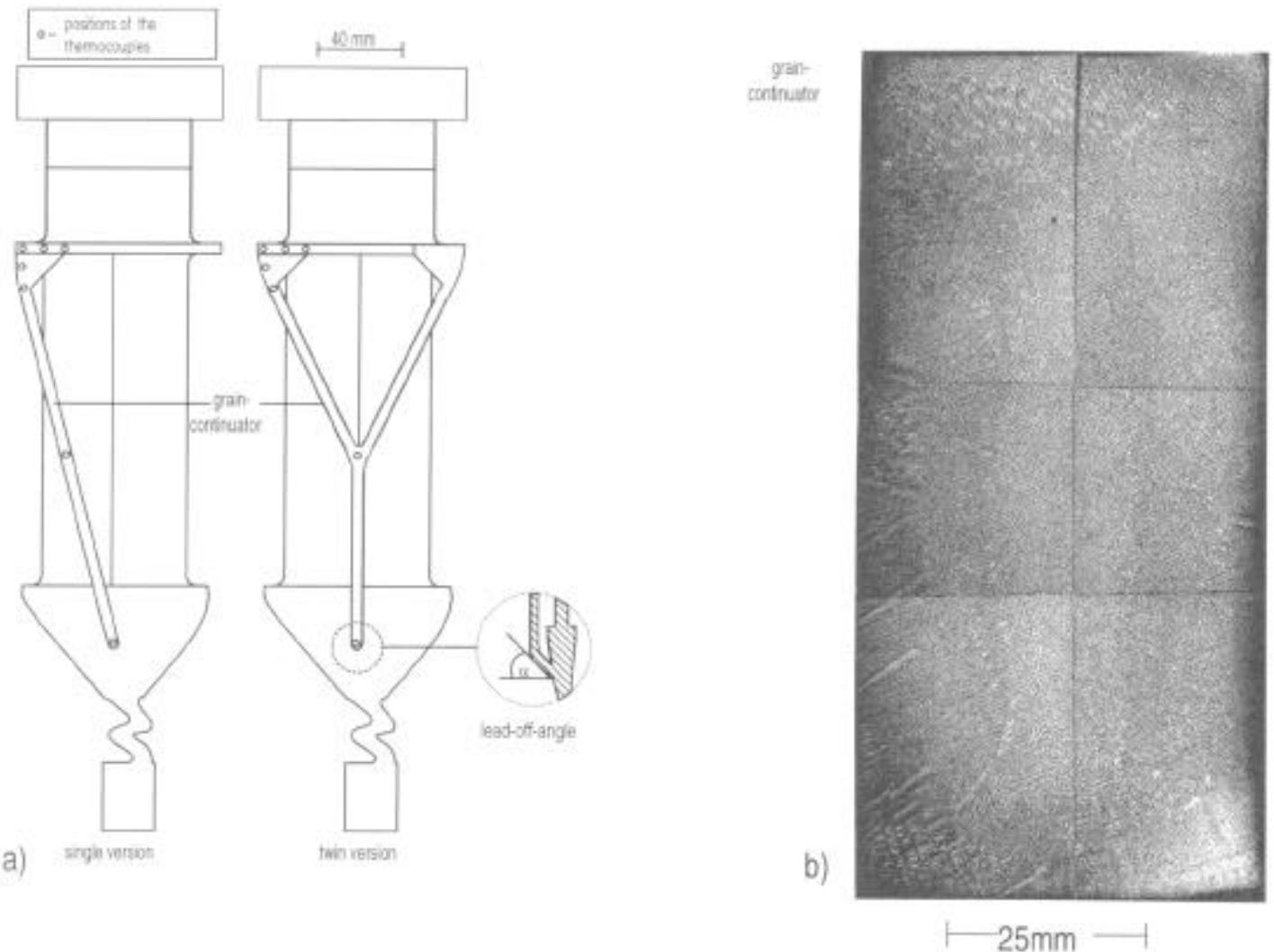

Figure 17: Single and twin version of the grain continuator casting set-ups (a). On the micrograph of single version casting (b) note the primary dendrite axes in the upper left hand corner where the continuator had been attached. 
the critical shroud regions by optimizing the profile of the withdrawal velocity. The application of grain continuators is not required for the chosen small geometry and the alloy CMSX-6.

For larger geometries and alloys that are not easily undercooled, in contrast, grain continuators seem to be unavoidable. They proved to be capable of minimizing undercooling related defects and are sometimes the only practicable means to avoid spurious grains in outer shroud regions. They have the disadvantage that they imply a relatively high technical expenditure and that they can cause low angle boundaries in the shroud due to crystal growth distortion during passage in the continuator. In this field further research is necessary in order to fully control the grain continuators' mode of operation.

\section{Acknowledgments}

This study was carried out as part of a project sponsored by the German Federal Ministry of Education and Research (BMBF 03M 3038 E7). The authors also like to thank Thyssen Guß AG Investment Casting (Bochum, Germany), MTU Munich (Germany) and ACCESS e.V. (Aachen, Germany) for support and discussion.

\section{$\underline{\text { References }}$}

1. D. Goldschmidt, U. Paul and P.R. Sahm, "Porosity Clusters and Recrystallisation in Single-Crystal Components", in Proc. of the 7 th International Symposium on Superalloys, eds. S.D. Antolovich et al., Seven Springs, PA, Sept. 2024,1992 , p. $155-164$
2. B. Paine, "Product Property of Superalloys by DS and SX Castings", AETC Symposium 1986, AE-Group

3. S.L. Cockcroft, M. Rappaz, A. Mitchell, J. Fernihough, A. Schmalz, "An Examination of Some of the Manufacturing Problems of Large Single-Crystal Turbine Blades for Use in Land-Based Gas Turbines", in Proc. of Materials for Advanced Power Engineering, eds. D. Coutsouradis et al., Liège, 3-6 October 1994, p. 1145-1154

4. P.R. Sahm, W. Richter, F. Hediger, "Das rechnerische Simulieren und Modellieren von Erstarrungsvorgängen bei Formguß", Giesserei-Forschung, 35, 1983, Heft 2, p. 35-42

5. F. Hediger and N. Hofmann, "Process Simulation For Directionally Solidified Turbine Blades of Complex Shape", in Proc. of the 5th Intern. Conference on Modeling of Casting. Welding and Advanced Solidification Processes, Davos, Switzerland, Sept.16-21, 1990, eds. M. Rappaz et al., Warendale: TMS 1991, p. 611-619

6. R. Siegel and J.R. Howell, Thermal Radiation Heat Transfer (McGraw-Hill Book Company, New York, 2nd Edition, 1981)

7. A. Yoshinari, K. Iijima, I. Takahashi and H. Kodama, "Solidification Simulation for Large Single Crystal Buckets in Heavy Duty Gas Turbines", in Proc. of Modeling of Casting and Solidification Processes, eds. C.P. Hong et al., 1991, p. 201-212 